\begin{tabular}{|c|c|c|c|c|c|c|}
\hline & & $R A(n=352)$ & AS $(n=442)$ & \multicolumn{2}{|l|}{ PSA $(n=133)$} & p-value ${ }^{*}$ \\
\hline \multicolumn{2}{|c|}{ Female } & $257(73.0 \%)$ & $104(23.5 \%)$ & $58(43.6 \%)$ & \multicolumn{2}{|r|}{$<0.001^{\mathrm{ABC}}$} \\
\hline \multicolumn{2}{|c|}{ Disease duration } & $7.1 \pm 5.7$ & $7.0 \pm 6.7$ & $7.5 \pm 7.2$ & \multicolumn{2}{|r|}{0.245} \\
\hline \multicolumn{2}{|c|}{ Age at start of anti-TNF therapy } & $47.2 \pm 8.9$ & $39.5 \pm 8.6$ & $44.4 \pm 9.1$ & \multicolumn{2}{|r|}{$<0.001 \mathrm{ABC}$} \\
\hline \multicolumn{2}{|l|}{$\mathrm{HAQ}$} & $1.5 \pm 0.5$ & $1.2 \pm 0.5$ & $1.2 \pm 0.6$ & \multicolumn{2}{|r|}{$<0.001^{\mathrm{AB}}$} \\
\hline \multirow{2}{*}{\multicolumn{7}{|c|}{$\begin{array}{l}\text { Post-hoc analysis (with Bonferroni correction): statistically significant difference btw groups A) } \\
\text { RA vs. AS, B) RA vs. PSA, C) AS vs. PSA. Values or } N(\%) \text { or mean (SD). }\end{array}$}} \\
\hline & & & & & & \\
\hline $\mathrm{Dg}$. & WPAI-SHP component & Baseline & 12 months & $\begin{array}{l}\text { Mean change } \\
\text { after } 12 \text { months }\end{array}$ & $\mathrm{N}^{\dagger}$ & P-value* \\
\hline \multirow[t]{4}{*}{$\mathrm{RA}$} & Absenteeism & $12.8(27.9)$ & $5.1(18.5)$ & $7.7(30.3)$ & 203 & $<0.001$ \\
\hline & Pres & & $27.6(20.9)$ & $24.5(26.3)$ & 183 & $<0.001$ \\
\hline & Overall work impairment & 53.9 & $28.7(22.0)$ & $25.2(26.9)$ & 183 & $<0.001$ \\
\hline & Activity impairment & 62.4( & $36.0(23.0)$ & $26.4(27.7)$ & 352 & $<0.001$ \\
\hline \multirow[t]{4}{*}{ AS } & Absenteeism & $10.6(25.6)$ & $3.5(15.8)$ & $7.1(28.0)$ & 307 & $<0.001$ \\
\hline & Prese & $53.1(22.2)$ & $21.1(18.0)$ & $32.0(24.9)$ & 282 & $<0.001$ \\
\hline & Overall work impairment & $54.8(22.6)$ & $21.8(18.8)$ & $33.0(25.5)$ & 281 & $<0.001$ \\
\hline & Activity impairment & $60.7(22.1)$ & $27.3(21.4)$ & $33.5(26.4)$ & 442 & $<0.001$ \\
\hline \multirow[t]{4}{*}{ PSA } & Absenteeism & $5.7(17.3)$ & $4.2(18.4)$ & $1.5(24.6)$ & 90 & 0.135 \\
\hline & Presenteeism & $43.9(24.0)$ & $15.3(16.2)$ & $28.6(24.5)$ & 84 & $<0.001$ \\
\hline & Overall work impairment & $45.2(25.0)$ & $15.9(16.8)$ & $29.3(25.1)$ & 84 & $<0.001$ \\
\hline & Activity impairment & $57.4(24.6)$ & $26.2(21.3)$ & $31.2(26.5)$ & 133 & $<0.001$ \\
\hline
\end{tabular}

${ }^{\dagger} \mathrm{N}=$ Number of assessed patients. Values are mean \% (SD). ${ }^{*}$ Wilcoxon paired test for difference between baseline and 12 months within each WPAI score.

$69 \rightarrow 64 \%, p=0.013)$, but not in AS $(77 \rightarrow 78 \%)$ or PSA $(77 \rightarrow 73 \%)$. In patients employed for pay both at baseline and after 12 months, all WPAI-SHP scores improved significantly over one year of anti-TNF therapy (Table 2).

Conclusions: In the real life setting of the Czech Republic, anti-TNF therapy effectively reduced absenteeism, presenteeism, activity impairment and work impairment over one year in employed patients with RA, AS and PSA.

Disclosure of Interest: None declared

DOI: 10.1136/annrheumdis-2017-eular.4339

\section{THU0651 SHOULD WE REDUCE THE DOSE OF BIOLOGICAL THERAPY TO ALL PATIENTS WITH INFLAMMATORY ARTHRITIS ACHIEVING SUSTAINED THERAPEUTIC GOAL?}

I. Gonzalez-Alvaro ${ }^{1}$, C. Sánchez-Piedra ${ }^{2}$, R. Almodovar ${ }^{3}$, J. Bachiller ${ }^{4}$, A. Balsa ${ }^{5}$, A.J. Blasco ${ }^{6}$, R. Caliz ${ }^{7}$, G. Candelas ${ }^{8}$, C. Fernández-Carballido ${ }^{9}$, A. García-Aparicio ${ }^{10}$, B. García-Magallón ${ }^{11}$, R. García-Vicuña ${ }^{1}$,

A. Gomez-Centeno ${ }^{12}$, A.M. Ortiz ${ }^{1}$, R. Sanmartí ${ }^{13}$, J. Sanz ${ }^{14}$, B. Tejera ${ }^{15}$ I. Notario ${ }^{7}$, M.J. Soto ${ }^{7}$, C. Plasencia ${ }^{5}$, V. Hernández ${ }^{15}$, M. Espinosa ${ }^{14}$, C. Ramos ${ }^{14}$, P. Lazaro ${ }^{6} .{ }^{1}$ Rheumatology, HU la Princesa: ${ }^{2}$ Research Unit, SER, Madrid; ${ }^{3}$ Rheumatology, HU Fundación Alcorcón, Alcorcón; ${ }^{4}$ Rheumatology, HU Ramon y Cajal; ${ }^{5}$ Rheumatology, HU la Paz; ${ }^{6}$ Independent Health Services Researcher, Madrid; ${ }^{7}$ Rheumatology, HU Virgen de la Nieves, Granada; ${ }^{8}$ Rheumatology, Hospital Clínico San Carlos, Madrid; ${ }^{9}$ Rheumatology, Hospital General Universitario, Elda: ${ }^{10}$ Rheumatology, Hospital Virgen de la Salud, Toledo; ${ }^{11}$ Rheumatology, Hospital Gral San Jorge, Huesca; ${ }^{12}$ Rheumatology, HU Parc Taulí, Sabadell; ${ }^{13}$ Rheumatology, Hospital Clinic, Barcelona;

${ }^{14}$ Rheumatology, HU Puerta de Hierro, Majadahonda; ${ }^{15}$ Rheumatology, HU Canarias, Sta Cruz Tenerife, Spain

Background: Dose tapering of biological therapies (BT) in patients with rheumatoid arthritis (RA) or spondyloarthritis (SpA) is frequent in Spain. However, there is variability in BT optimization (BTO). So, Spanish Society of Rheumatology published in 2015 recommendations on how to optimize BT (1). Nevertheless, there is no solid evidence on which patient profiles BTO is appropriated.

Objectives: To develop appropriateness criteria for BTO in patients with RA, axial $\mathrm{SpA}(\mathrm{axSpA})$ or peripheral $\mathrm{SpA}(\mathrm{pSpA})$

Methods: The RAND/UCLA appropriateness method was used. Five rheumatologists experienced in RA and/or SpA clinical research selected and defined the variables considered relevant when deciding reduction of $\mathrm{BT}$ in order to define patient profiles. Ten BT experienced rheumatologists anonymously rated 1 (completely inappropriate) to 9 (completely appropriate) each profile after reading evidence synthesis. Then, in a meeting, classification variables and profiles with disagreement were revised and all profiles were scored again. Profiles with a median score $>6$ were considered appropriate, those with a median score $<3.5$ were considered inappropriate and the remaining uncertain. In addition, a study of the prevalence of these profiles was performed in 9 Spanish hospitals.

Results: Combining the options of variables 2,304 different profiles were obtained for RA, 768 for axSpA, and 3,072 for pSpA. $327(14.2 \%)$ profiles in RA, 80 $(10.4 \%)$ in axSpA, and $154(5 \%)$ in pSpA were considered appropriate for BT dose reduction. By contrast, $749(53.3 \%)$ profiles in RA, $270(54.4 \%)$ in axSpA, and $1243(54.5 \%)$ in pSpA were considered inappropriate. The remaining profiles were considered uncertain. In the preliminary study to determine profiles prevalence, we collected information from 242 RA, 171 axSpA and 172 pSpA patients that underwent BTO. We found that BTO was performed appropriately in $23 \%$ RA, $67 \%$ axSpA and $61 \%$ pSpA patients. BTO was indicated in uncertain profiles in $67 \%$ RA, $23 \%$ axSpA and $37 \%$ pSpA patients. Only in RA we detected BT dose reduction in patient profiles considered inappropriate $(2 \%)$
Conclusions: Appropriateness criteria for BT dose reduction in three inflammatory conditions were developed and the preliminary prevalence study suggests that BTO was wiselly applied. However, further research in this field is needed to determine the real prevalence of clinical profiles of patients undergoing BTO in daily clinical practice and validate these criteria in real life.

References:

[1] Gonzalez-Alvaro I et al. Rheumatology 2015; 54: 1200-1209.

Disclosure of Interest: I. Gonzalez-Alvaro: None declared, C. Sánchez-Piedra Grant/research support from: Unrestricted grant from Abbvie, R. Almodovar: None declared, J. Bachiller: None declared, A. Balsa: None declared, A. Blasco Grant/research support from: Unrestricted grant from Abbvie, R. Caliz: None declared, G. Candelas: None declared, C. Fernández-Carballido: None declared, A. García-Aparicio: None declared, B. García-Magallón: None declared, R. García-Vicuña: None declared, A. Gomez-Centeno: None declared, A. Ortiz: None declared, R. Sanmartí: None declared, J. Sanz: None declared, B. Tejera: None declared, I. Notario: None declared, M. Soto: None declared, C. Plasencia: None declared, V. Hernández: None declared, M. Espinosa: None declared, C. Ramos: None declared, P. Lazaro Grant/research support from: Unrestricted grant from Abbvie

DOI: 10.1136/annrheumdis-2017-eular.3836

\section{THU0652 ASSESSMENT OF BIOSIMILARS USING REAL WORLD DATA: THE COMPLEXITY OF CHOOSING A COMPARATOR AND UNDERSTANDING UPTAKE}

D. Di Giuseppe ${ }^{1}$, T. Frisell ${ }^{1}$, S. Ernestam ${ }^{1}$, H. Forsblad-d'Elia ${ }^{2}$, E. Lindqvist ${ }^{3}$,

U. Lindström ${ }^{4}, C$. Sjöwall ${ }^{5}$, J. Askling ${ }^{1}$ on behalf of the ARTIS group.

${ }^{1}$ Department of Medicine Solna, Karolinska Institutet, Stockholm; ${ }^{2}$ Umeå

University, Umeå; ${ }^{3}$ Lund University and Skåne University hospital, Lund;

${ }^{4}$ Sahlgrenska Academy, University of Gothenburg, Göteborg; ${ }^{5}$ Linköping

University, Linköping, Sweden

Background: The introduction of biosimilars has been linked with concerns regarding how to best monitor their similarity vs. the originator product using real world data.

Methods: Data from the Swedish Rheumatology Quality register (SRQ) was used to identify all patients with rheumatoid arthritis (RA), ankylosing spondylitis (AS), psoriatric arthritis ( $\mathrm{PsA})$, and other spondyloarthropathy $(\mathrm{SpA})$, who started a treatment with infliximab (originator Remicade or biosimilars Remsima or Inflectra) between 1st Mar 2015 and 30th Sept 2016 or with etanercept (originator Enbrel or biosimilar Benepali) between 1st April 2016 and 30th Sept 2016.

Results: During the study period, a total of 1833 patients started an infliximab treatment and 1793 started etanercept. These patients were either bDMARDnaïve (patients without a history of any biological treatment), non-medical switchers (patients who switched from the originator product), or patients who had a history of a previous (but not the same) bDMARD (Table 1). These three groups were not evenly distributed across originators or biosimilars, and had different baseline demographic and disease characteristics.

The uptake in terms of treatment starts was faster for Benepali (it covered more than $90 \%$ of this part of the etanercept market after only 3 months) as compared to Remsima and Inflectra (together they accounted for $88 \%$ of this section of the infliximab market after 10 months). The uptake of biosimilars in terms of proportion of all patient on treatment was, at the end of September 2016, 27\%

Table 1. Number of patients starting infliximab (from 1 March 2015 to 30 September 2016) or etanercept (from 1 April 2016 to 30 September 2016) originator or biosimilar, by line of treatment

\begin{tabular}{lccccc}
\hline & \multicolumn{2}{c}{ Infliximab } & & \multicolumn{2}{c}{ Etanercept } \\
\cline { 2 - 3 } \cline { 6 - 7 } & Originator & Biosimilars & & Originator & Biosimilar \\
\hline Total & 570 & 1263 & & 186 & 1607 \\
Bio- naïve & $379(66 \%)$ & $508(40 \%)$ & & $89(48 \%)$ & $581(36 \%)$ \\
Non-medical switchers & - & $524(42 \%)$ & & - & $710(44 \%)$ \\
Switchers from other biologics & $191(34 \%)$ & $231(18 \%)$ & & $97(52 \%)$ & $316(20 \%)$ \\
\hline
\end{tabular}

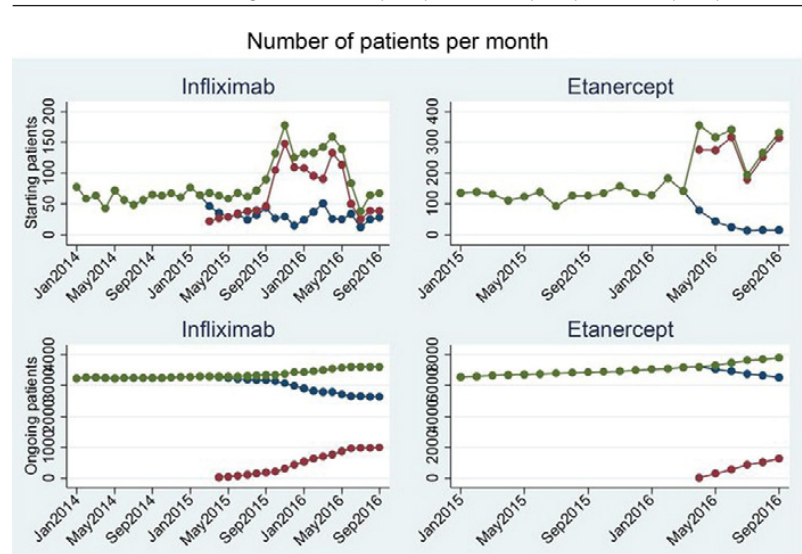

Figure 1. Number of patients starting, and on, respectively, infliximab or etanercept by month Green: total, red: biosimilar, blue: originator. 
of all infliximab (after 18 months of marketing) and $16 \%$ of etanercept (after 5 months since marketing).

In contrast to the bio-naïve group and those with a history of a previous (but not the same biologic), there was no readily available comparator group for the non-medical switcher group. To this end, we assessed three tentative definitions for a comparator; i) a historical comparison, i.e., same patients 18 months before the switch, ii) an individually matched sample of those patients still on originator treatment at the time of the switch, and iii) the total cohort of those who had not switched.

Conclusions: "Uptake" of biosimilars can be expressed both as proportion of all new starts and as proportion of ongoing treatments. Assessments of uptake, and any comparison between biosimilars and their originators, need to be based on line of therapy in order to avoid mixing up effects of channeling with true differences between originator and similar. For the same reason, any originator comparator for non-medical switchers needs to be reflective of those patients who stood the same chances of switching, but did not switch.

Disclosure of Interest: D. Di Giuseppe: None declared, T. Frisell: None declared, S. Ernestam: None declared, H. Forsblad-d'Elia: None declared, E. Lindqvist: None declared, U. Lindström: None declared, C. Sjöwall: None declared, J. Askling Grant/research support from: Abbvie, BMS, Pfizer, MSD, Roche, Samsung, Lilly DOI: 10.1136/annrheumdis-2017-eular.4651

\section{THU0653 PREVENTING RHEUMATOID ARTHRITIS: A GENERAL POPULATION PILOT STUDY ON PERSPECTIVES OF THE RISK OF DEVELOPING THE DISEASE AND POTENTIAL PREVENTATIVE INTERVENTIONS}

M. Harrison ${ }^{1,2}$, N. Bansback ${ }^{1,2}$, L. Spooner ${ }^{1}$, K. Milbers ${ }^{2}$, C. Koehn ${ }^{3}$, M. Hudson ${ }^{4}$. ${ }^{1}$ University of British Columbia; ${ }^{2}$ Centre for Health Evaluation and Outcome Sciences; ${ }^{3}$ Arthritis Consumer Experts, Vancouver; ${ }^{4}$ McGill University, Montreal, Canada

Background: Evidence suggests that treatment of people at risk of rheumatoid arthritis (RA) with anti-rheumatic drugs could prevent the onset of disease, and there are ongoing randomized controlled trials on the efficacy of preventing RA. However even if these trials are successful, there will be uncertainty around the potential benefits of these programs in practice; namely, the ability to predict those at risk of RA, exact benefits and risks, and inconvenience of treatment. Objectives: To determine the features of a preventative treatment program that are likely to be acceptable to pre-symptomatic people at high risk of RA. Our focus is on preferences for treatment, the values and most important attributes of a preventative treatment program, and the likely uptake of preventative treatment. In this pilot study we sought general population preferences.

Methods: A discrete choice experiment was administered to a US general population sample, asking participants to choose between sets of 2 hypothetical preventative RA treatments, then between their preferred treatment and "no treatment for now". The treatment (risk of developing RA, how treatment is taken, chance of side effects, certainty in estimates, health care provider's opinion) and test attributes (chance test is wrong, who recommends treatment) were identified in focus groups with RA patients, first-degree relatives of RA patients and rheumatologists. An efficient experimental design was developed using SAS and included 2 consistency checks. Responses were analyzed using a conditional logit regression model to estimate the significance and relative importance of attributes in influencing preferences.

Results: 201 respondents completed the survey. The majority of the sample was 25-54 years old (modal age category: $30-39$ years (38\%)) and 50\% were female. 23 members $(11 \%)$ reported having a physician diagnosis of RA, and 91 (45\%) had a family member or close friend with RA. All attributes' levels significantly influenced treatment preferences, but risk reduction, how treatment is taken, and health care provider preference were most influential. Respondents were most willing to trade a reduction in risk of RA for a treatment preferred by their health care professional and an oral route of administration. Respondents had a similar strength of preference for reducing uncertainty in evidence and reducing the risk of side effects. The preferred preventative treatment was chosen over no treatment in $67 \%$ of choices.

Conclusions: Our survey suggests that people value the potential benefits of treatments, but equally values how the treatment is taken and the preference of their health care provider. The degree of confidence in the estimates of a treatment's risks and benefits is as important to people as the risk of side effects. The uptake of a preventative strategy will depend on these key factors. This evidence will help policymakers understand whether different preventative treatment strategies are likely to be acceptable to people they are offered to.

Acknowledgements: This work was supported by a grant from the Canadian Rheumatology Association through the Canadian Initiative for Outcomes in Rheumatology Care (CIORA).

Disclosure of Interest: None declared

DOI: 10.1136/annrheumdis-2017-eular.2170

\section{THU0654 THE INFLUENCE OF RISK PRESENTATION FORMAT ON WILLINGNESS TO START A MEDICATION}

R. Cozmuta $^{1}$, L. Fraenkel ${ }^{2}$, E. Wilhelms ${ }^{3}$, V. Reyna ${ }^{4}$, J. Nolte ${ }^{4} .{ }^{1}$ Emory University, Atlanta; ${ }^{2}$ Yale University, New Haven; ${ }^{3}$ Vasser College, Poughkeepsie, NY; ${ }^{4}$ Cornell University, Ithica, NY, United States

Background: Patients with rheumatoid arthritis frequently refuse to escalate care because they overweight the probability of adverse events. Effectively communicating risk information to patients is difficult. Several approaches have been developed to facilitate comparative risks; however, recent data suggest that current approaches have a limited impact on risk perceptions and willingness to take medication.

Objectives: The objective of this study was to examine whether an icon array (IA), an illustration of the gist of how medications regulate the immune system (a series of balance beams), or both influence willingness to start a medication.

Methods: Patients with a rheumatic disease were mailed a survey in which they were asked to imagine that their symptoms had worsened and that their physician was recommending a new medication. We varied the probability of an adverse event (pneumonia requiring hospitalization): $2 \%$ or $0.2 \%$, and the risk presentation format: numbers, numbers + IA, numbers + balance beams (BB), or numbers + both. Route of administration, benefit, and cost were held constant. Each subject responded to a single, randomly-assigned scenario. We controlled for socioeconomic status (SES), using a variable including both difficulty paying for medications as well as education, in a full-factorial model testing willingness to take the medication (measured on a 5-point scale).

Results: Of 1453 surveys, 465 patients completed the survey. Overall, the mean (SD) age was 59.0 (14.8); $79.7 \%$ were female; $83.2 \%$ White and $39.1 \%$ were classified as having low SES. There were no statistical differences in patient characteristics across the risk presentation formats. Willingness to start the medication was predicted by the interaction between the risk presentation format and SES ( $F=2.9, p=0.03$ ). Willingness by SES status is described in the Figure 1. Among low SES subjects, addition of an IA did not affect willingness compared to the numbers-only format. In contrast, addition of BB (mean difference $=0.47$, $p=0.07$ ), or both IA and BB increased willingness (mean difference $=0.48, p=0.04$ ). Among high SES subjects, addition of an IA or BB or both did not influence willingness compared to the numbers only format. However, both formats including an IA increased willingness compared to the BB format among high SES subjects (mean difference $\mathrm{IA}$ vs $\mathrm{BB}=0.53, \mathrm{p}=0.01$; mean difference $\mathrm{I} A$ vs $\mathrm{IA}+\mathrm{BB}=0.48$, $\mathrm{p}=0.02)$.

Figure 1. Willingness across Formats by SES

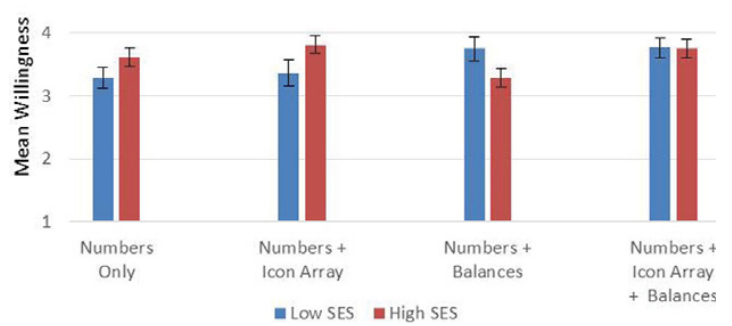

Conclusions: SES affects how subjects respond to risk presentation formats. IA marginally increases willingness in high SES subjects, while BB increases willingness in low SES subjects; when both $I A$ and $B B$ are present, SES differences disappear. BB, when not accompanied by an IA, may decrease willingness in high SES subjects. These results demonstrate the differential effects of risk presentation formats, and highlight the need to identify mechanisms underlying their effects when implementing decision-support tools.

Disclosure of Interest: None declared

DOI: 10.1136/annrheumdis-2017-eular.5169

\section{THU0655 DO VISUAL DECISION AIDS HELP PATIENTS CORRECTLY DIFFERENTIATE BETWEEN A $2 \%$ AND A $0.2 \%$ RISK?}

R. Cozmuta ${ }^{1}$, L. Fraenkel ${ }^{2}$, E. Wilhelms ${ }^{3}$, V. Reyna ${ }^{4}$, J. Nolte ${ }^{4} .{ }^{1}$ Emory University, Atlanta; ${ }^{2}$ Yale University, New Haven; ${ }^{3}$ Vasser College, Poughkeepsie, NY; ${ }^{4}$ Cornell University, Ithica, NY, United States

Background: Studies have found that patients ignore probabilities when making treatment decisions.

Objectives: The objective of this study was to examine whether addition of an icon array (IA), a series of three consecutive balance-beam (BB) illustrations depicting how medications regulate the immune system, or both resulted in patients being able to better differentiate between an uncommon $(2 \%)$ and rare $(0.2 \%)$ adverse event $(\mathrm{AE})$.

Methods: Patients currently being treated for a chronic inflammatory rheumatic disease were mailed a survey in which they were asked to imagine that their symptoms had recently worsened and that their physician was recommending a new medication. The medication was described using eight scenarios (manipulated using a $2 \times 4$ design). We varied the probability of a serious AE (pneumonia 